\title{
How to change the unchanging? Restructuring Polish universities for the XXI century
}

\author{
R. Robert Gajewski \\ Faculty of Civil Engineering, Warsaw University of Technology, Poland
}

\begin{abstract}
The rapid development of new information and communication technologies has implications for higher education and training. University leaders need to be aware of the opportunities and threats linked to advances in new technologies. All Polish universities are confronting similar challenges and common constraints: limited financial resources and high expectations from society. There are also big pressures for changes as well as resistance.
\end{abstract}

Key words: open and distance learning, e-learning, life-long learning, courseware, teacher education, distributed learning

\section{PRELIMINARY REMARKS}

One of the pressures on universities is the rapid development of new information and communication technologies (ICT) for the provision of education and training. Wide opportunities in open and distance learning (ODL) create new markets. Moreover, the principle of life-long learning (LL) extends the age groups to which a university can offer education. Additionally the principles of the new techniques can be applied to traditional markets - regular intramural students. It means that the potential created by new technologies for teaching and learning requires discussion concerning a university's aims and objectives.

A clear distinction should be made between the quality of the means of delivery of a course and the quality of the content of the course. Until now all research into the quality of the ODL has been rather technology-driven rather than pedagogy-driven. Monitoring and student evaluation of remote tutoring should certainly be undertaken.

The original version of this chapter was revised: The copyright line was incorrect. This has been corrected. The Erratum to this chapter is available at DOI: 10.1007/978-0-387-35615-0_52 
Two well-known teaching paradigms from the literature have their limitations: chalk and blackboard (Classroom-based Learning, CbL) and computerisation (Technology-based Training, TbT) (Gajewski, 1999). I am deeply convinced that a new paradigm which I call Web-based Learning (WbL) could become an educational standard for the XXI century.

\section{CHALLENGES FOR POLAND}

There are several major external economic, political and social pressures on universities in Poland nowadays:

- A reduction in the willingness of the public to pay more for university education. Funding is decreasing and moreover state universities are supposed to do more with less money.

- A demand on the universities to equip people with the skills for LL. Universities must cope with increasing heterogeneity among students and offer more choices of learning paths.

- A commercialisation of knowledge. This generates opportunities for new markets as well as threats from new competitors to universities.

- The impact of the information age. Universities no longer have a monopoly on the production and transfer of knowledge.

\section{OPPORTUNITIES AND CONSTRAINTS}

All Polish universities willing to use modern information and communication technologies face common opportunities, threats and constraints (Gajewski, 1997).

Rapid changes in educational technologies well known in Poland from the literature are in my opinion an opportunity to change the higher education on offer from a teacher-centred and paper-based environment to a learner-centred and network-based model. The question of how to perform this is still open. Modern teaching tools could improve the quality of teaching and learning, mainly by helping to create and develop individual learners. From my point of view this is the biggest motivation for universities to introduce new technologies. Multimedia and web technologies give more choices of learning paths. Moreover there is a possibility for universities to play a role in accreditation of courses offered by commercial competitors.

Advances in ICT and the increase of available information to everybody provoke fears of a non-structured mass of information which would not be managed by a university. Moreover this leads to the judgment that 
universities no longer hold a monopoly on the creation of knowledge and on its transmission. There are many new competitors on the education market such as consortia of telecommunication companies with software companies and the entertainment industry. This situation can be treated as a threat, but as far as I am concerned, it is also very stimulating. The last danger is that the use of ICT may increase rather than reduce the gap between students and teachers. Teachers can lose contact with better-skilled students. Personally I believe that a 'paperless' virtual university does not mean a 'teacherless' university.

The telecommunication infrastructure in Poland is not as good as in other European countries or America. The transmission capacity of the telematic infrastructure is poor in Poland. This can cause problems not only for students. Teaching material takes a long time to develop. Then it needs to be regularly updated, which can be troublesome.

Another Polish constraint is the cost of using new technologies in teaching, and how to use and reuse resources in an efficient way. The most obvious cost associated with new technologies is physical infrastructure cost - hardware and peripherals. We undertook a first step: our computer laboratories were redecorated and quite well equipped with mid-grade computers, basic software and multimedia projectors.

What we face now offers a dilemma: to buy more computers, or to buy necessary software. All the expenses spent on ICT require continuous upgrading. In addition, training, supplies and personnel require investment and the costs of necessary courseware are extremely high. Multimedia and web-based course development is expensive compared with traditional course delivery (an estimate given by the Technical University in Lisbon is 100 to 400 hours of preparation per multimedia hour).

The high cost of multimedia or web-based courseware production implies the need for intensive reuse of the courses. Such products must target audiences wider than those of traditional student classes. While initial investment costs are high, economies of scale can be expected. Once fixed costs have been met, the additional costs decrease rapidly. The more widespread the courses, the more economic the operation (Forsyth, 1999).

\section{PRESSURE VERSUS RESISTANCE}

A constant struggle between pressure for change and fear and resistance to change is visible in Poland. There is an internal brake on the efforts to bring about change through using new technologies: resistance from people.

Teachers' attitudes are a major obstacle to the introduction of change. Reference can be made to 'a frozen middle' resisting attempts at change from 
both the top of the institutions (authorities) and from the bottom (students). When it comes to creating course packages there is no motivation for an academic to get involved in a process for which there is little or even absolutely no reward.

Students' demands are a powerful factor forcing universities to exploit the potential of new technologies to improve the learning experience. A new type of computer-skilled student is arriving at the university and expecting teaching staff to be equally skilled. ICT is moreover part of a students' leisure time.

\section{CONCLUSIONS AND FINAL REMARKS}

Universities no longer have a monopoly on knowledge. They have to compete with educational corporations or enterprises. Moreover students are more likely to take into account the communications infrastructure and the modernity of the learning environment than the content of courses. Polish universities need to think more about the place of new learning techniques in their institutional strategies.

\section{REFERENCES}

Forsyth, I. (1999) Teaching and Learning Materials and the Internet. London: Kogan Page Gajewski, R.R. (1997) Network learning and WWW: hardware, software and human barriers. Proceedings of the Fourth International Conference on Computer Aided Engineering Education, III/4-6, Krakow, Poland.

Gajewski, R.R. (1999) Effective WWW-based training: towards the virtual teacher. Computer

Methods in Civil Engineering, 4, 71-82

\section{BIOGRAPHY}

R. Robert Gajewski, Ph.D., is an assistant professor in the Centre of Computer Methods at the Faculty of Civil Engineering at Warsaw University of Technology. He gives lectures in applied informatics, computer methods, and structural and computational mechanics. His research covers two main fields: (i) the application of computational techniques to structural engineering problems, and (ii) the usage of information and communication technologies in education and training. He has published nearly fifty papers in international journals and conferences. 